\title{
ANÁLISIS HISTÓRICO: PASADO Y PRESENTE DE CIUDAD SANDINO
}

Verónica Mejía Flores

\begin{abstract}
Resumen:
El ensayo "Análisis bistórico: pasado y presente de Ciudad Sandino" tiene como propósito indagar el contexto bistórico de esta población, caracterizando la vida desde sus orígenes basta la actualidad, abordando sus diferentes aspectos sociales, culturales, políticos, administrativos y territoriales. El estudio permite identificar los problemas que ba tenido la población en su desarrollo como comunidad. Para ello, fue necesaria la utilización de Historia Oral para construir aquellas fuentes no registradas por medio de escritos y que son determinante para la comprensión de la evolución del municipio. Por medio de los testimonios expuestos por los babitantes, protagonistas de la bistoria del municipio, se analizó y sintetizó la información requeridas para la reconstrucción, rescate y comprensión de los cambios suscitados en su evolución. En este trabajo se reflejan los antecedentes bistóricos, comparando pasado y presente utilizando fuentes bibliográficas y orales para determinar los elementos que todavía persisten en la práctica de la cotidianeidad. A manera de conclusión se destaca que este territorio ba presentado significativos cambios observables en el crecimiento poblacional e infraestructura del municipio, permitiendo bacer comparaciones entre un inicio muy difícil y un presente promisorio.
\end{abstract}

Palabras clave: Marginalidad; Historia Oral; bistoria del municipio, testimonios.

\begin{abstract}
:
This "Past and Present Historical Analysis of Ciudad Sandino" essay aimed to inquire the bistorical context of this population, by characterizing population way of living since the beginning to the present, addressing its social, cultural, politics and administrative aspects. The research allows to identify those problems that the population bas bad in its development. One of the sources was oral bistory to capture not registered sources, which are very important to understand town evolution. Through analyzing testimonies of Inbabitant protagonist and bibliographical sources allow the reconstruction, recovery and understanding of changes during their evolution. This work shows bistorical background comparing past and present to determine those practices in that persist in everydayness. As a conclusion it stands out has significant changes have occurred in Ciudad Sandino town. This are population growth and infrastructure, which have allowed comparison from a very difficult beginning to a promising present.
\end{abstract}

Keywords: Marginality; Oral History; township bistory, testimonials.

Quiero comenzar mi ponencia adhiriéndome a una verdad sabida por muchos, de la importancia de las fuentes bibliográficas en los proceso de validación de las investigaciones científicas, agregando además, que las fuentes orales complementan aquella información no han registrada en soporte alguno.

El presente trabajo titulado Pasado y presente del municipio de Ciudad Sandino (aproximaciones históricas) hace uso de ambas fuentes, de tal manera que se pueda contrastar lo escrito con los testimonios de los pobladores acerca de la historia de este emblemático municipio del Departamento de Managua.

El estudio tiene como propósito la comprensión de la evolución histórica del municipio, desde sus orígenes como asentamiento de emergencia, su condición de barrio marginal y su elevación a municipio de gran dinamismo en la actualidad. Como se dijo anteriormente, el estudio se apoya en los escritos y testimonios de pobladores representativos de esta gran comunidad, estableciendo los aspectos más relevantes que contribuyeron a la configuración del rostro actual de este conglomerado social.

Las técnicas utilizadas para este estudio fueron las entrevistas grabadas, observación directa y convivencia en el municipio (observación participante). De igual manera, se hizo trabajo documental y bibliográfico, relacionado al tema. Los Métodos implementados tienen que ver con el histórico-lógico, análisis y síntesis, y por supuesto la historia oral, esta última indispensable para 
reconstruir la vida cotidiana de sus habitantes en sus diferentes etapas evolutivas.

Una de las razones que justifican este estudio, tiene que ver con la forma en que este Municipio se fue "haciendo", las vicisitudes y carencias sufridas por sus habitantes durante ese proceso de construcción, pero también la perseverancia y su espíritu de lucha demostrada en su corta vida como conglomerado social. Podría decirse que apenas cuenta con unos 50 años de vida, desde aquellos, tiempos difíciles de los años 60, pero llenos de grandes experiencias históricas y socioculturales que son las que se pretende con este trabajo que hoy presento.

Otros de propósitos que justifican este trabajo es el contribuir a ampliar las fuentes para el estudio del municipio y estimular nuevos acercamiento a nuevas temáticas. Hasta el momento se cuenta con pocos estudios relacionados con el municipio, todos ellos de caracteres anecdóticos, periodísticos y otros de carácter sociológicos, sobre aspectos puntuales (diagnósticos) de poca utilidad para la comprensión de su historia y de sus avatares y de su identidad como colectividad social.

\section{¿Historiando? mejor dicho conociendo}

El concepto de historia ha evolucionado de manera sustantiva en los últimos tiempos. Se pasó de una historia "acontecimental" (évenémentiel), narrativa (positivista) a una que apela a la reflexión a partir de métodos y técnicas que buscan la comprensión lo más objetiva posible, de la vida de los seres humanos, su origen y desarrollo a través del tiempo. Dentro de estos nuevos enfoques de la historia es pertinente citar la siguiente: "La historia es la memoria de la humanidad y sus pueblos, es el esfuerzo por entender la vida de los seres humanos, su origen, desarrollo y desenvolvimiento en la tierra a través del tiempo". (Colección Difusión; 2012:19).

Una de las especialidades en los estudios históricos, tiene que ver con la temática regional y local, cuyo enfoque y métodos, ayudan a la comprensión de manera exhaustiva de los componentes identitarios, apelando a la memoria colectiva de la comunidad. En este sentido, podemos afirmar que "El estudio histórico de nuestra región y localidad nos permite rescatar la memoria colectiva, revitalizando el sentido de pertenencia de los pobladores por su historia y espacio cotidiano al conectar a los individuos con los macrofenómenos [sic] históricos..." (Colección Difusión; 2012:22. Esta cita hace referencia a la importancia de estos enfoques regionales, las diversas dimensión que pueden adquirir estos estudios y su aplicabilidad en estudios de casos.

La Historia local es el estudio de la historia a pequeña escala, cuyo centro de interés es un territorio específico, las comunidades. De igual manera, este enfoque comprende el conjunto de habitantes de un lugar determinado, por tanto, la historia del municipio de Ciudad Sandino, antiguo barrio marginal de la periferia de la vieja Managua, se presta para este estudio dentro de esta caracterización.

La palabra marginado y marginalidad pueden tener diferentes acepciones y percepciones en dependencia del estudio y enfoque con que se utilice. Para Cuadra quien tiene un estudio sobre el municipio de Cuidad Sandino, "... Marginalidad es la condición en que vive un sector de población sin tener conciencia de clase ni sentido de historia, atendiendo únicamente el problema de una precaria subsistencia, al margen del avance, el desarrollo y la atención pública del resto de habitantes...". (1973: 1).

Partiendo del supuesto de Cuadra, entendemos por marginalidad como el estado de vulnerabilidad, exclusión y condición precaria de subsistencia, en la cual los nuevos habitantes de un territorio se adaptan. Ellos buscan sobrevivir en medio de problemas relacionados con la pobreza, tratando de encontrar respuestas a las limitaciones del medio, como la falta de agua potable, energía eléctrica, acceso a calles o carreteras, etc. Esta condición era la que imperaba entre los pobladores iniciales de Ciudad Sandino, bautizada en aquel entonces como OPEN III.

\section{En el recuerdo de los fundadores}

La historia oral es el rescate del pasado de los seres humanos a través del testimonio, sustentados por experiencias y vivencias pasadas susceptibles de analizar y reconstruir. Cada persona tiene una experiencia única e irrepetible, en relación a los hechos vividos, siendo esa condición, la que le da la riqueza a los estudios históricos con enfoque oral.

Esta condición de los estudios históricos con enfoque oral, me ha llevado a interesarme en la historia de Ciudad Sandino, cuyo comienzo complejo, difíciles, y en general diferente a los de otras experiencias de municipios o comunidades, son las que guían este trabajo. Fresco aún en la memoria de los fundadores sobrevivientes y de la primera generación nacida en el municipio, las causas que los llevaron a asentarse 
en esta zona al occidente de Managua. Las lluvias torrenciales prolongadas por días, producto de una depresión tropical a mediados del año de 1969, hizo que el o Xolotlán (lago de Managua) creciera e inundara los barrios pobres asentados a en sus costas, como Miralagros, la Tejera, Quinta Nina, Acahualinca y otros ubicados a orillas del lago Xolotlán.

Las inundaciones del año 69, hizo que el gobierno del General Anastasio Somoza Debayle (1925-1980), tomara medidas ante esta emergencia, realizando un operativo de reubicación de las familias afectadas. Entre las medidas tomadas estaba el traslado de los afectados, en tres etapas, creándose con ello tres asentamientos: OPEN I (hoy América I), OPEN II (Villa José Benito Escobar) y OPEN III (Ciudad Sandino). A los pobladores de este último asentamiento, se les reubicó en el kilómetro 12 1/2 carretera nueva León, en tierras cuyo propietario era el somocista y terrateniente Julio Blandón. El nombre de OPEN hace alusión a un plan de reubicación que el gobierno implementó con el fin de enfrentar la crisis provocada por los aguaceros de ese entonces: Operación Permanente de Emergencia Nacional.

Los propietarios de las tierras donde se asentaron los damnificados, la familia Blandón, las utilizaban para el cultivo del algodón y ajonjolí. Al respecto, Cuadra expone: "Estas tierras eran unas doscientas manzanas que formaban la hacienda de Santa María y San Juan. Pertenecían a los hermanos Blandón..." (1973: 19). De esta manera sabemos también que estas tierras estaban habitadas por trabajadores de estos hacendados: "los famosos Blandón... tenían sus trabajadores, sus mandadores, sus peones, a como ellos le llamaban" (Marchena: 2014).

Los terrenos seleccionados para la creación del nuevo asentamiento, no contaba con las condiciones mínimas para construir viviendas, por las características de ser una hacienda. Cuando comenzaron a llegar las primeras familias, se encontraron con mojones y unas trochas rústicas (semi patroneadas) que indicaban los límites de los lotes a poblar. La extensión de estos era diez varas de frente por treinta de fondo, lo paradójico del caso (de familias muchas de ellas desempleadas), era que no eran donados, sino vendidos al crédito, por un valor de 3000 córdobas, con una mensualidad de 10 al mes.

En principio se puede nombrar e identificar del OPEN III al conocido como "Bella Cruz", en la actualidad perteneciente a la zona ocho del Municipio de Ciudad Sandino. El origen de esta zona urbana se debe a familias vinculadas a los terratenientes quienes Análisis histórico: Pasado y presente de Ciudad Sandino les cedieron tierras, en una especie de colonato. Los primeros años de vida de los habitantes del nuevo asentamiento, fue difícil. Les invadía un sentimiento de incertidumbre, ante las carencias de una mínima infraestructura de servicios básicos: agua potable, energía eléctrica, transporte público, escuelas, fuentes de empleo cercanas y seguridad ciudadana, porque no se contaba con un puesto policial permanentes, ni un puesto de salud para atender emergencias mínimas. El autor Barreto afirma: "En los primeros dias, por supuesto, comenzaron varios dramas que serian luchas inolvidables en los próximos meses y años: los asuntos del agua, el transporte, la comunicación, la luz eléctrica, el teléfono, las calles y demás servicios elementales como salud y educación". (2001: 13).

En la memoria colectiva de la población han quedado registrados los habitantes, hoy considerados por ellos mismos, como pioneros por su beligerancia para organizar a los pobladores y demandar antes las autoridades del Municipio y del Estado, derechos a servicios básicos. Entre estos personajes se recuerda al jesuita, padre Miguel, el señor Gilberto Barberena, Carlos Masis (el cabro) y Alberto Aguilar conocido como "El Gato Aguilar".

Una de las problemáticas más sentidas por la población fue la falta de agua potable. Los pobladores iniciales de este Municipio, recuerdan las dificultades que pasaban todos los días para adquirir un barril de agua con el cual cocinar, bañarse y lavar la ropa. El propietario del principal pozo de agua era la familia Blandón, quien se lucraba vendiendo el agua. Años después, los curas jesuitas, también harían un pozo, y de igual manera vendían el agua, aunque a un precio más accesible.

El cambio de domicilio de muchas de estas familias, alejada de sus habituales ambientes donde se habían criado o vivido por generaciones, a la orilla del lago, les obligó a adaptarse de manera rápidas a la nueva realidad. Los que contaban con empleo o una forma de ganarse la vida, no lo abandonaron sino que debieron trasladarse hasta los lugares de trabajo, lo cual generaba tensión, dado que se carecía con un sistema de transporte colectivo que llegar hasta el asentamiento. Para solventar esa carencia, debían caminar hasta la carretera Nueva a León (distancia que fluctuaba entre $1 / 2$ a $2 \mathrm{~km}$ ), y tomar los buses interurbanos (los que iban a Mateare, Nagarote o La Paz Centro).

Conforme el paso de los años se comenzó a improvisar un sistema de transporte conformada por camionetas de tina, las cuales comenzaron a Verónica Mejía Flores 
dar el servicio hacia Managua. De la investigación "Origen y desarrollo del municipio y ciudad Sandino 1969 a la actualidad", se encuentra que: "La vaquita transportaba pasajeros del OPEN 3 hacia la cuesta el plomo, y del OPEN 3 a las piedrecitas con un ñalor de 1 órdoba por pasaje, este funcionaba de cinco de la ma ana a 6 de la tarde" (Rodríguez: 2015), este fue el primer medio de transporte perteneciente al territorio pero dada la velocidad con que se poblaba el nuevo asentamiento y la necesidad se agudizaba, comenzó a circular una empresa de buses (Ruta 13) cuyo propietario era el Coronel Victorino Lara. Es importante destacar que antes del terremoto, esta ruta, ya circulaba cuya terminal era el Mercado Central, pasando por el mercado Bóer.

El terremoto (diciembre de 1972) que destruyó Managua, generó otro enormeéxodo de damnificados. Las autoridades edilicias y el Comité de Emergencia Nacional, presidido por el General Somoza, fomentó el traslado de familias al asentamiento OPEN III. La llegada de miles de familias, haría aceleraría el proceso de urbanización y aumentaría las demandas de servicios básicos.

Una de las demandas más sentidas, además del agua, después del terremoto, sería las mejoras en el sistema de transporte. La ruta 113 no daba abasto para trasladar a una masa de trabajadores (informales o formales) que había aumentado en poco tiempo de manera exponencial. El propietario de la concesión de la ruta, sabiendo esta situación, permitía que operara con libertad un sistema de camionetas, las cuales en sus inicios llegaban hasta el parque Las Piedrecitas. Años después, al igual que los buses llegarían a una nueva terminal: el mercado Oriental. Este mercado, secundario y pequeño antes del terremoto, absorbería a los comerciantes y locatarias del destruido Mercado Central.

\section{Siguen las luchas hasta 1979: Lo que pasó, pasó...}

Como anteriormente se ha mencionado, la tragedia del terremoto que destruyó la capital la noche del 23 de diciembre de 1972 dejaría cuantiosas pérdidas materiales, económicas y sobre todo humanas. Miles de familias perdieron sus casas, teniendo que ser trasladas a diferentes zonas en las afueras de la ciudad, con el pretexto de evitar epidemias debido a los cadáveres aún enterrados entre los escombros. Las zonas más afectadas de la ciudad fueron cercadas no permitiendo la circulación peatonal ni vehicular.

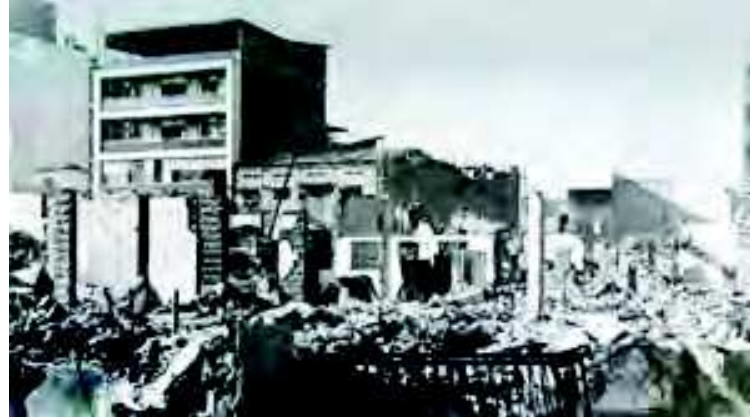

Foto 1. Terremoto de Managua, diciembre 1972 (El Nuevo Diario)

Como también se ha dejado constancia, El OPEN III fue una de las respuestas del gobierno de Somoza, para solucionar el grave problema de los damnificados. Esta catástrofe natural podría decirse que es la causa más importante para explicar el poblamiento y el rumbo social y político que este conglomerado social. Después del terremoto, la fisonomía de asentamiento comenzará a cambiar, dando paso a un barrio marginal, dinámico y con personalidad propia. Pese a su condición de barrio marginado, el OPEN III desde sus inicios se caracterizó por contar con habitantes dispuestos a luchar por las reivindicaciones consideradas justas y necesarias. Un ejemplo de ello es el protagonismo que tuvieron los pobladores durante la lucha contra la dictadura somocista. Durante la insurrección de septiembre de 1978 y la ofensiva final de junio-julio de 1979, grupos de jóvenes y adultos, tuvieron un papel activo en los desiguales combates contra la Guardia Nacional, siendo respaldados por la mayoría de los habitantes.

Muchos de los pobladores de finales de la década del 70 recuerdan las jornadas de lucha contra Somoza, la cual se expresaba en movilizaciones y mítines que reivindicaban el derecho a los servicios básicos: agua, luz. Mejoras de las calles. Movilizaciones apoyadas por las tendencias del FSLN, movimientos sociales, entre ellas las Comunidades Eclesiales de Base.

\section{La revolución y la llegada del cambio}

Con el triunfo de la Revolución Popular Sandinista el 19 de julio de 1979, las nuevas autoridades de gobierno deciden como una de las primeras medidas tomadas, cambiar el nombre de OPEN III a barrio "Ciudad Sandino". Esta decisión obedeció, según cuentan los pobladores, a la iniciativa del cantautor nicaragüense "El Gato Aguilar", habitante del barrio, quien, junto a otros pobladores, el 17 de julio de este mismo año, y escuchándose todavía las detonaciones de las balas y bombas, colocó una manta en la entrada donde se leía: Ciudad Sandino. Esta acción refrendada por 
el gobierno revolucionario representa un punto de inflexión en la conformación de la identidad de los habitantes del Municipio.

Se considera que el nombre de Ciudad Sandino es en honor del General Augusto C. Sandino. Pinell' expresa que "nace el Frente Sandinista de la lucha histórica y heroica del general de hombres libres Augusto César Sandino... es un icono y de alli se basa el nombre..." (Pinell, 2014). Esto influyó tanto, que en la entrada al municipio se encuentra edificado un monumento al precursor de la lucha sandinista.

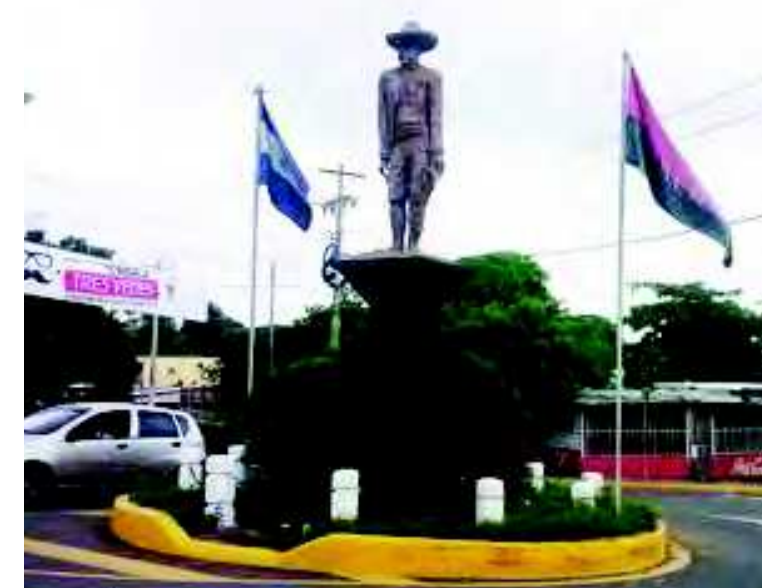

Foto 2. Estatua del General de hombres y mujeres libres, Augusto C. Sandino. Entrada al municipio que lleva su nombre. Verónica Mejía Flores (2014)

De manera permanente la gesta libertaria del general Sandino ha sido una inspiración para el pueblo que posee un sentimiento de patria, apropiándose de su pensamiento nacionalista. Bajo una coyuntura político-social y económica desfavorable, se encuentra un pueblo luchador y revolucionario que se identifica claramente con el más representativo defensor de la soberanía nacional, por lo tanto es un privilegio portar este nombre y un reconocimiento público a tan incansable héroe que no pedía nada para sí mismo.

La revolución fue un detonante de cambios en todo el territorio nacional, El gobierno revolucionario instaurado, intervino en el OPEN III pocos días después; produciéndose las confiscaciones de las propiedades somocistas y la mediación de los reportes ilegales de deudas con la familia o guardias somocistas; los habitantes que todavía tenían que pagar obtuvieron condonación de su deuda aunque la pobreza todavía continuaba. Se intervino la ruta
113 de Victorino Lara y se organizaron otras rutas urbanas. (Rodríguez: 2015).

Se conforman nuevas cooperativas de rutas colectivas como: 210 Etramol, 115 Esfuerzos democráticos y nueva unidad y esfuerzos, 133 Copetecss, la 125 y 172 pertenecen a la cooperativa Marlon Zelaya.

\section{Pasado reciente}

¿Cómo se comprometió Ciudad Sandino social y culturalmente en los años ochenta? El gobierno de Nicaragua, surgido del triunfo de la Revolución Popular Sandinista de 1979, pretendió reducir el nivel de analfabetismo de nuestro país que en ese momento alcanzaba más del $50 \%$. Estudiantes de Ciudad Sandino asumieron su compromiso social al integrarse a la Cruzada Nacional de Alfabetización. Según Pinell: "Ciudad Sandino jugó un papel importante, hubo una gran cantidad de gente que participamos en la Gran Cruzada Nacional de Alfabetización y lógicamente eso fue el logro más importante de la Revolución, porque eso es lo que hace desarrollar a los paises... la gran mayoría de los estudiantes salieron fuera del territorio de Ciudad Sandino..." (Pinell; 2014).

Esta acción pretendía educar a aquellos que no sabían leer y escribir, llegando a crear conciencia que un pueblo educado es un pueblo que tiene identidad y cultura. Como dice el himno de la Cruzada Nacional de Alfabetización: "convirtiendo la oscurana en claridad".

Durante las décadas de los ochenta (1980) y los noventa (1990), se experimentó un crecimiento económico-social y una expansión geográfica. Ciudad Sandino ha pertenecido al departamento y al municipio de Managua, por lo tanto estaba sujeta económica, política y administrativamente a este.

La realidad demostraba que las necesidades iban en aumento y se profundizaban los problemas sociales. Por otro lado, Managua como metrópolis no daba cobertura a Ciudad Sandino en sus peticiones básicas, trayendo como consecuencia que la población decidiera independizarse de esta administración. En este contexto, en 1995, los habitantes presentaron ante la Asamblea Nacional de Nicaragua la solicitud de aprobación de una Ley que elevara el Distrito al rango de Municipio, Pero fue hasta el año 2000 que

1. Manuel Pinell, alcalde municipal de Ciudad Sandino durante el período (2002-2005) y actual alcalde para el período 2014-2016.

2. Este hallazgo se sitúa en la Zona Siete de Ciudad Sandino, en la comunidad de Oro Verde en el año 2012. 
se aprobó y publicó en la Gaceta, la Ley No. 329, elevando al distrito a la categoría de municipio.

Otro factor que incrementó el número de población, fue el huracán Mitch, en el año de 1998. Este fenómeno natural, afectó las costas del lago de Managua e impulsó un nuevo movimiento poblacional hacia Ciudad Sandino.

\section{Mi diversión, mi pasión}

La cultura tiene muchos significados interrelacionados entre sí. Esta es la preservación de identidades individuales y colectivas, tradiciones, normas, valores sociales, creencias, saberes y pautas de conducta de un grupo social, así como rasgos esenciales que nuestros pueblos van tejiendo en su propia identidad local.

Desde sus orígenes hasta la actualidad, Ciudad Sandino se ha caracterizado por ser una sociedad diversa y heterogénea. Los pobladores recuerdan cómo se divertían los fines de semana. Muchos asistían al cine que estaba ubicado en la zona No. 2, para ese tiempo estaba el auge las películas chinas (de Kung-fu). Este representaba uno de los principales medios de entretenimiento para la población; llegando al extremo de hacer chistes de él, diciendo que llevarían un casco para reguardar sus cabezas.

Otros iban a las fiestas que promocionaban en el Colegio Roberto Clemente Fe y Alegría, que estaba coordinado por monjas jesuitas.

Durante los años ochenta se creó el centro recreativo "La Cachorra", una casa comunal donde se realizaban fiestas los fines de semana y actividades culturales. Por este lugar pasaban recreándose los jóvenes que andaban movilizados en la montaña, en el Servicio Militar Patriótico "Los cachorros". Actualmente lo consideran un patrimonio cultural y se está reconstruyendo.

Han existido otros centros de diversión como los fueron: el club "El Esfuerzo", "La Cueva”, "El Planeta”, "El Remembranza" y bares como los "Chacalines" y "Cachiro". Actualmente existen lugares de recreación familiar como el parque de la zona No. 8, la plaza de Ciudad Sandino conocida como Padre Miguel, antes llamada plaza de Los Cabros, en honor a Carlos Masi "El Cabro", quien poseía cabros y los dejaba en esta zona.
Como parte del legado histórico-cultural en Ciudad Sandino encontramos la iglesia San Francisco Javier (La Cruz grande), fue la primera iglesia, la llaman Cruz grande porque tiene una cruz hecha de cemento que la identifica. Actualmente funciona como colegio, y se ubica en el centro de Ciudad Sandino, también la iglesia de Bella Cruz y el actual museo "Sandino" que posee piezas arqueológicas como estatuillas, esqueletos, etc., son considerados como parte de nuestro legado.

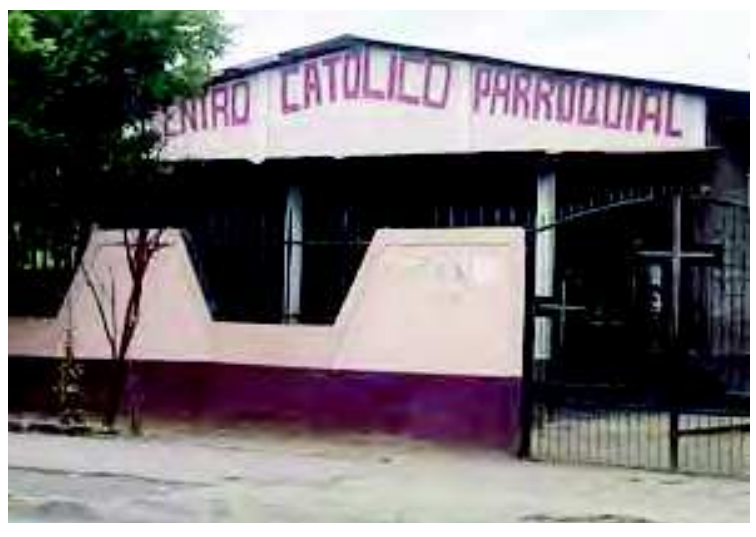

Foto 3. Iglesia San Francisco Xavier, conocida como "Cruz Grande" Verónica Mejía Flores (2014).

Uno de los descubrimientos más significativos fue el de un cementerio indígena de entierro secundario ${ }^{2}$. El tipo de piezas se relacionan a una especie de pequeñas urnas funerarias elaboradas con material cerámico. En Ciudad Sandino han existido varios hallazgos, que han contribuido a nuestra cultura.

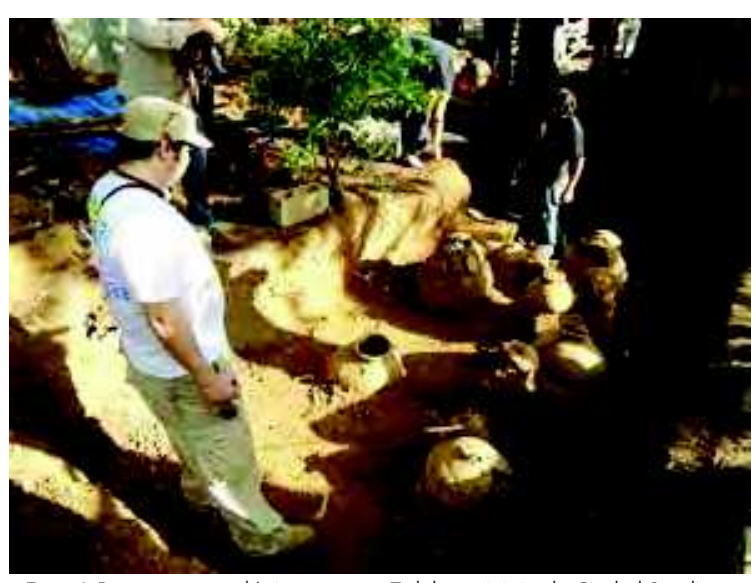

Foto 4. Rescate arqueológico en zona 7 del municipio de Ciudad Sandino. Frances Aburto (2012). 
La fiesta patronal que caracteriza a la población es en honor a Santo Domingo de abajo, que tienen lugar el 8 de agosto de cada año. Durante esta se representan la costumbre y tradición que posee una parte de los pobladores.

Muchos centros culturales se han levantado desde los orígenes del municipio, impulsados por organizaciones no gubernamentales como el Centro de Integración y Capacitación Maura Clarke (CECIM) y el Centro de Educación y Comunicación Popular (CANTERA), siendo los más importantes y representativos de la comunidad donde siempre han enseñado pintura, música, danza, etc. Todos promueven la participación de niños, jóvenes y adultos.

La cultura se refleja en el arte de la apreciación por la danza que se ha fomentado en Ciudad Sandino, formándose muchos grupos de danzas, por ejemplo el que dirige la alcaldía. Hasta en las escuelas se enseña a danzar la música tradicional (El baile Folklórico).

La forma de diversión para los ciudadanos ha cambiado, pues cuando era el OPEN III "El Gato Aguilar" salía por las noches a realizar cantatas para animar a la población, entonando sus canciones (Pinell: 2014). Actualmente los niños, jóvenes y adultos tienen otras áreas de diversión y distracción en el municipio, por ejemplo realizan competencias de futbol que promueven la equidad, trabajo colaborativo, apoyo y solidaridad entre los mismos, también se realizan los juegos de la zona No. 8 (en el parque) y los que organizan en el mercado de Ciudad Sandino, etc.

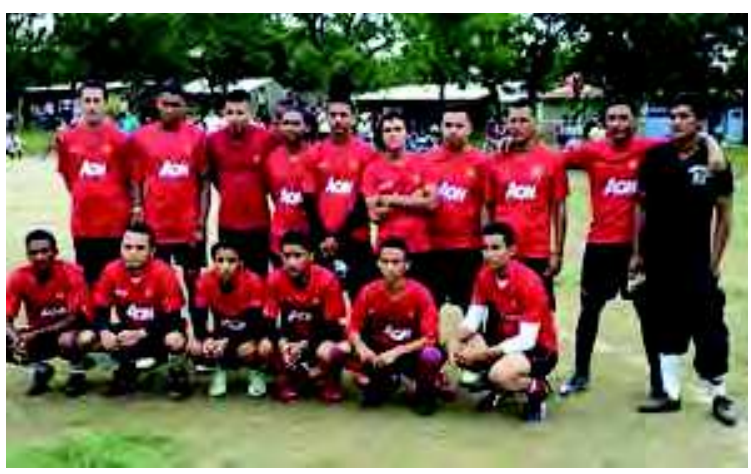

Foto 5. Equipo juvenil de fútbol de Ciudad Sandino.

Orlando Mejía Flores (2012).

Una manifestación de la cultura se muestra a través de su propio escudo municipal e himno: El escudo: La franja que rodea todo el escudo encierra los tres principios que marcan al municipio como es la honestidad, el servicio y desarrollo, siendo características la honra, la disposición y el trabajo. En la parte inferior se lee el nombre del municipio Ciudad Sandino; dentro de este se representa el cerro Motastepe. El sol brillante sobre el cerro y sus nubes simbolizan el estado natural climático que ha caracterizado. El himno muestra la manera de vida que tuvieron los pobladores del conocido OPEN III y su lucha por sobrevivir.

De la marimba de chavalos de la Tirsa este tal Quincho se las gana a los demás con sus diez años no cumplidos todavía es hombre serio, como pocos en su edad. Mientras su mama se penquea en la rebusca Quincho se faja como todo un tayacán mañana y tarde vende bolís en los buses para que puedan sus hermanos estudiar. Que viva Quincho, Quincho Barrilete, héroe infantil de mi ciudad, que vivan todos los chavalos de mi tierra, ejemplo vivo de pobreza y dignidad. Que viva Quincho, Quincho Barrilete su nombre, no se olvidará, porque en las calles, plazas, parques y barriadas el pueblo lo repetirá. Joaquín Carmelo viene a ser solo un membrete que le pusieron en la pila bautismal, pero su nombre de combate es Barrilete le cae al pelo, con su personalidad. Allá en el Open, vive desde el terremoto, a hacer lechuzas este Quincho es un campeón, por un chelín, te hace un cometa prodigioso para ponerle un telegrama al colochón.

El tiempo sigue, incontenible, su camino y el chavalito que vivió en el Open tres no volverá a ponerse más pantalón chingo ni la gorrita con la visera al revés. Un día va a enrollar la cuerda del cometa y muy feliz mirando al sol se marchará enfrentará las realidades de su pueblo y con los pobres de su patria luchar.

Un valor incalculable es la pertenencia que tienen en la manifestación de la cultura. El cantar su himno y conocerlo es parte de la vida diaria de cada uno de los pobladores de Ciudad Sandino. Este canto expresa los comienzos y las penurias que vivieron los ciudadanos del OPEN III; que en medio de todo, sigue la alegría, las ganas de triunfar y luchar para una vida mejor, y sobre todo Ciudad Sandino es ejemplo vivo de pobreza y dignidad.

\section{Actividades socioeconómicas de los pobladores}

La actividad económica ha cambiado por la creciente influencia del sector terciario, que son los servicios comerciales (formales e informales), los cuales con el paso del tiempo han permitido ganarse la vida vendiendo, sacaban a la acera de sus casas las ventas de productos manufacturados, pequeñas bisuterías o comiderias. Así se fue conformando el mercado 
de Ciudad Sandino, donde los productores de frutas y verduras llegaban a instalarse para ofertar sus productos; con la creciente necesidad de tener cierto orden, en la década de los ochenta empiezan las construcciones para el local que sería el mercado, este "Se inauguró el 12 de octubre de 1981, cuenta con 300 comerciantes que atienden a la población, posee su propia instalación del sistema de agua potable y su reacondicionamiento del parque vehicular para la construcción del área de carga y descarga" (Rodríguez; 2015).

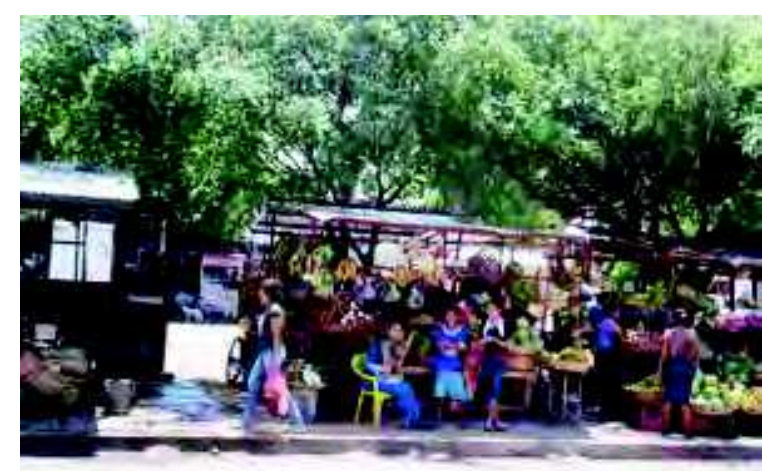

Foto 6. Mercado de Ciudad Sandino. Jahoska Sarely Lezama (2014).

La calle principal es zona comercial, pues en ella se ubican muchos centros de compras y ventas de diferentes índoles, como el PALÍ, Banco (BANPRO), Casas de Empeño (CREDIFAST), Ópticas de la vista, ventas de alimentos, barberías, ferretería, etc. A nivel de infraestructura, las instituciones municipales han tenido un cambio muy significativo, esto se ve reflejado en edificaciones como la Alcaldía Municipal, Policía Nacional, estación de Bomberos, colegios, Comisaría de la Mujer, y hospital general; para este último, hay planes de proyectarlo como un hospital de mayor envergadura en todos los aspectos.

Una dificultad que se percibe es la mala infraestructura de las calles, pues en temporada de invierno se dan las comunes inundaciones y el acceso a las calles se vuelve casi imposible. El mal hábito de tirar basura es una de las principales causas, ya que provoca que los cauces se inunden. Esto se debe a la falta de interés por parte de la población; sin embargo, poco a poco se ha ido cambiando este hecho, y regulándose los botaderos ilegales en el municipio.

\section{Conclusiones}

Para concluir, hay que recalcar que Ciudad Sandino ha evolucionado de una manera sorprendente y ha presentado significativos cambios; de un asentamiento marginal, se convierte en un barrio y luego treinta años después lo elevan a rango de municipio. Esto refleja que la historia de la comunidad ha dado una vuelta de trescientos sesenta grados, alcanzado un mayor desarrollo para los habitantes, ya sea por el crecimiento de densidad poblacional que empuja a ensanchar las fronteras y espacios no habitados, infraestructura del municipio.

Ciudad Sandino ha estado marcada por luchas incansables de restitución de derechos, dignidad y una vida mejor, tratando de dar respuestas en los primeros años a la falta de recursos tan necesarios, venciendo obstáculos en medio de una sociedad represiva (la época de la dictadura somocista), con miedo quizás, pero dispuesto a darlo todo el bien de su comunidad.

Conforme al paso de los años, los habitantes han adquirido un sentido de pertenencia y compromiso social en todos los aspectos relacionados a su comunidad y su entorno geográfico. Esta condición ha hecho florecer una identidad colectiva manifestada en las prácticas culturales, en la participación social por medio de organizaciones y conmemoraciones de efemérides y otras actividades institucionalizadas.

\section{Referencias bibliográficas}

Cuadra, B. (1973). Actitudes y Valores de un barrio marginal OPEN N³, "Monografía". Nicaragua: Managua.

Barreto, E. (2001). Ciudad Sandino 31 años. Nicaragua: Alcaldía de Managua.

Arrechavala, J. (2008). Managua y su Historia: Un Enfoque Regional.1ra Edición. Managua.

Fonseca, R. (1997). Plan de Manejo de la Cuenca de Ciudad Sandino (PAMACS). Managua.

(1998).Proyecto "Microempresas de Manejo de dese chos sólidos y mejoramiento ambiental en el distrito I (ciudad Sandino)". Alcaldía de Managua: Managua.

Instituto Histórico Centroamericano y Nicaragua. (1981). Ciudad Sandino: su vida como barrio popular en la revolución.lra Edición. Managua.

Cruz, E. Rodríguez, R. Urbina, H. Valerio, V. (2013). Diagnóstico de la oferta turística de Ciudad Sandino Managua.

Historia, C. (2012). El pueblo cuenta su Historia. Venezuela

Rodríguez, F. Manzanarez, C. Manzanarez, A. (2014). Origen y desarrollo del municipio y ciudad Sandino 1969 a la actualidad. 


\section{Entrevistas en audio}

Marchena, J. (2014). [Entrevista realizada a José Marchena, Trabajador de la Alcaldía del Municipio de Ciudad

Sandino]. Grabación en Audio.

Ayerdis, M. (2014) [Entrevista a Miguel Ayerdis, Docente de la UNAN-Managua].Grabación en Audio.

Pinell, M. (2014). [Entrevista a Manuel Pinell, Alcalde del Municipio de Ciudad Sandino]. Grabación en Audio.

\section{Revistas}

Traña, M. (Septiembre 1991). "Breve Historia de los cementerios" de Managua (1865-1990). Revista de la colección Managua $\mathrm{N}^{\circ}$.

Pichardo, L. Historia del OPEN3 (ciudad Sandino). Revista de la colección Managua № 5. Institución rectora: División de cultura, historia y turismo de la alcaldía de Managua, 1-18.

\section{Anexo $\mathbf{N}^{\circ} 1$}

\section{Relación de entrevistas}

El siguiente cuadro posee información de un conjunto selecto de habitantes del lugar que nos interesa estudiar, cuyas experiencias y conocimientos son un aporte fundamental para la investigación titulada "Análisis Histórico: Pasado y presente de Ciudad Sandino" fueron entrevistados en el marco de Historia Regional y Local.

\begin{tabular}{|c|c|c|c|c|c|c|}
\hline $\begin{array}{l}\text { Tipo de en } \\
\text { entrevista }\end{array}$ & Apellido & Nombre & Fecha y hora & $\begin{array}{l}\text { Lugar de la } \\
\text { Entrevista }\end{array}$ & $\begin{array}{c}\text { Criterio de } \\
\text { selección }\end{array}$ & Oricio \\
\hline $\begin{array}{l}\text { Entrevista } \\
\text { grabadas } \\
\text { (Individual) }\end{array}$ & Marchena & Josêt & $\begin{array}{c}16 / 09 / 2014 \\
2: 00 \mathrm{pm}\end{array}$ & $\begin{array}{c}\text { Casa de habitación } \\
\text { zona \#11 en: } \\
\text { Ciudad Sandino del } \\
\text { Mercado } 9 \text { cuadras } \\
\text { al lago } 20 \text { varas al } \\
\text { Este. }\end{array}$ & $\begin{array}{c}\text { Partidario } \\
\text { politico }\end{array}$ & $\begin{array}{c}\text { Trabajador de la } \\
\text { Alcaldía municipal } \\
\text { de Ciudad Sandino }\end{array}$ \\
\hline $\begin{array}{l}\text { Entrevista } \\
\text { grabadas } \\
\text { (Individual) }\end{array}$ & Ayerdi & Miguel & $\begin{array}{c}25 / 09 / 2014 \\
5: 00 \mathrm{pm}\end{array}$ & $\begin{array}{c}\text { Oficina del anexo a } \\
\text { ta Faculta de } \\
\text { Humanidades y } \\
\text { ciencias juridicas } \\
\text { UNAN-Managua. }\end{array}$ & $\begin{array}{c}\text { Ex habitante } \\
\text { del de OPEN } \\
\text { III }\end{array}$ & $\begin{array}{c}\text { Docente del área } \\
\text { investigativa de la } \\
\text { Facultad de } \\
\text { Humanidades y } \\
\text { ciencias juridicas }\end{array}$ \\
\hline $\begin{array}{l}\text { Entrevista } \\
\text { grabadas } \\
\text { (Individual) }\end{array}$ & Pinell & Manuel & $\begin{array}{c}27 / 09 / 2014 \\
7: 00 \mathrm{pm}\end{array}$ & $\begin{array}{c}\text { Casa de habitación } \\
\text { zona \#4 en: Crudad } \\
\text { Sandino }\end{array}$ & $\begin{array}{c}\text { Alcalde y } \\
\text { fundador del } \\
\text { OPEN III }\end{array}$ & $\begin{array}{c}\text { Alcalde municipal } \\
\text { de Ciudad Sandino } \\
(2014-2017)\end{array}$ \\
\hline
\end{tabular}




\section{Anexo $\mathrm{N}^{\circ} 2$}

\section{Mapa de Ciudad Sandino}

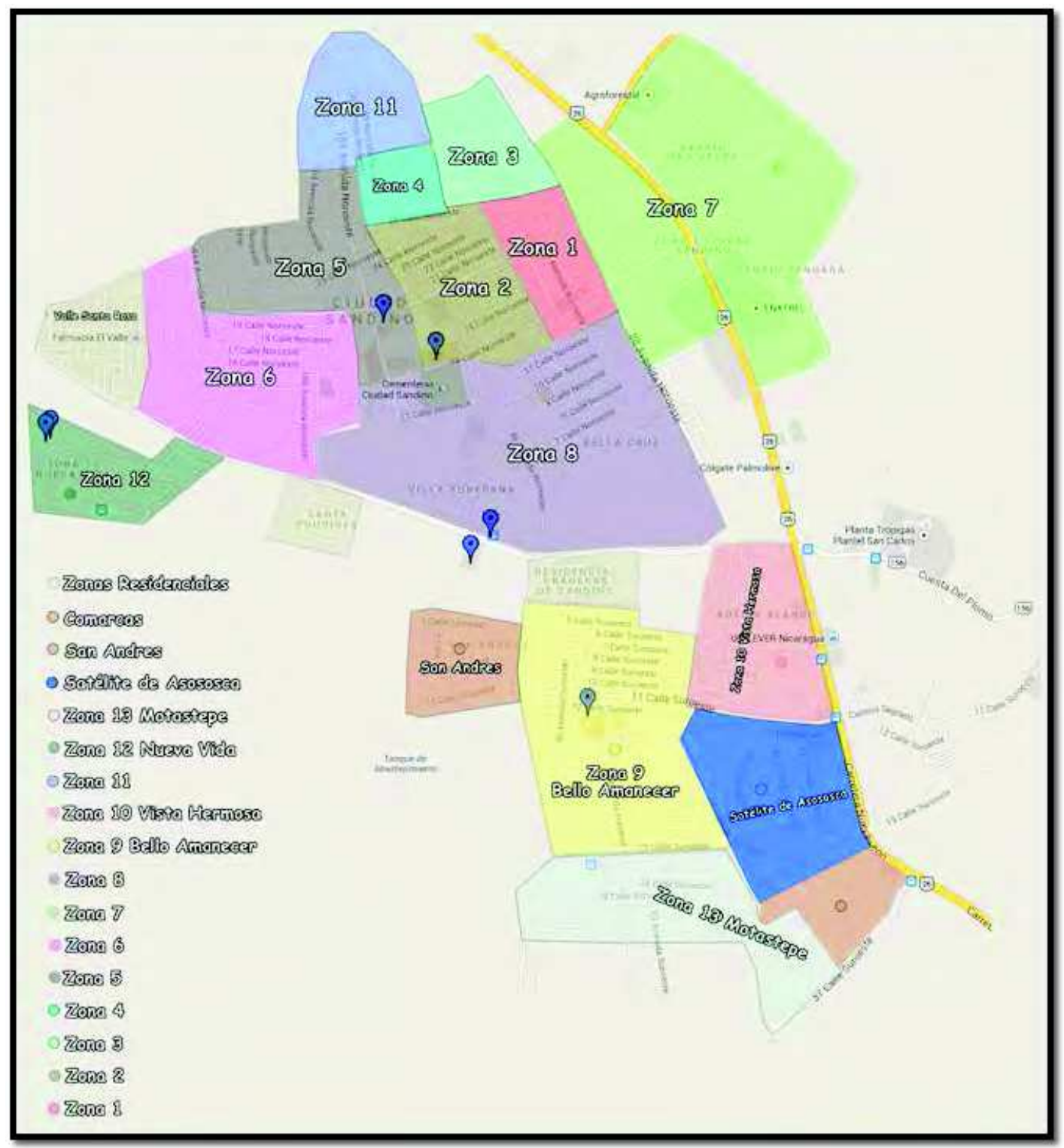

